\title{
LA REGULACIÓN EXPROPIATORIA EN LA JURISPRUDENCIA NORTEAMERICANA
}

\author{
RODRIGo DELAVEAU SWETT*
}

RESUMEN: El artículo expone la problemática acerca de la denominada regulatory takings o regulación expropiatoria, institución jurisprudencial del derecho anglosajón, en virtud de la cual se considera que el Estado hace una expropiación de facto a través de una regulación que reduce o elimina -sustancial o completamente- el valor de la propiedad, y que como consecuencia de dicha regulación debe indemnizar al afectado. Para ello, se estudia el origen de esta creación por parte de la Corte Suprema de los Estados Unidos, y se analizan los casos históricos más relevantes en esta materia, a la luz de los estudios que la doctrina de ese país ha realizado. En este trabajo se pretende establecer una teoría unificada que permita trazar un criterio uniforme para resolver cuándo estaríamos en presencia de una regulación expropiatoria. Finalmente, deja abierto el desafío para la recepción y desarrollo de dicha doctrina en el debate constitucional chileno.

Palabras clave: regulación expropiatoria, expropiacion regulatoria, regulación, expropiación, dominio eminente, derecho de propiedad, dominio, justa indemnizacion, compensación, derecho comparado, Quinta Enmienda, Constitucion de Estados Unidos, potestades publicas, uso de suelo, derecho urbanístico, derechos adquiridos, control de constitucionalidad.

ABSTRACT: This article explains the problem of so-called regulatory takings or expropiatory regulation, a common law institution created from caselaw, according to which the State uses a regulation to realize a de facto expropriation that -substantially or completely- reduces the value of the property, which implies, as a consequence of this regulation, that the State should compensate the owner. We study the origin of this creation by the Supreme Court of the United States and we analyze the most historically relevant cases on the subject, as well as the studies realized by the jurisprudence of that country. We aim at establishing a unified theory that would allow to find a uniform standard which would be helpful to decide where we are dealing with "regulation takings". Finally, it leaves the challenge open for reception and development of this concept with the Chilean constitutional debate.

Key words: regulatory takings, regulatory expropriation, regulation, expropriation, eminent domain, property right, dominion, just compensation, comparative law, Fifth Amendment, U.S. Constitution, authority, soil use, adquired rights, judicial review.

\section{INTRODUCCIÓN}

El desarrollo y la libertad de una sociedad y sus individuos dependen en gran medida del contenido y protección de los derechos de propiedad. En prácticamente

\footnotetext{
* Profesor de Derecho Constitucional, Pontificia Universidad Católica de Chile.
} 
todos los sistemas jurídicos se encuentra consagrada la indemnización a los particulares en el evento que el Estado les prive de su propiedad mediante un acto de expropiación. Siendo una de la primeras en reconocer dicha garantía, la Quinta Enmienda de la Constitución de Estados Unidos prohíbe al Estado expropiar bienes para uso público, sin el pago de una justa compensación a su propietario. La aplicación de dicho requisito es relativamente fácil de cumplir cuando la Administración ejerce formalmente la privación de propiedad a un particular, especialmente cuando se trata de bienes inmuebles. Cabe preguntar, entonces, si debe indemnizarse cuando las regulaciones del Estado han limitado -sin una expropiación formal- mediante la restricción normativa de los modos en que pueden usar su propiedad. Esta es la doctrina de la regulación expropiatoria ${ }^{1}$, en cuya virtud se plantea que mientras en una expropiación tradicional el Estado priva física y formalmente a un propietario de su dominio, en el caso de una regulación expropiatoria se sostiene que el Estado hace efectiva una expropiación de facto a través de una regulación que reduce o elimina sustancial o completamente el valor de la propiedad. En este sentido, se conjuga el dominio eminente del Estado ${ }^{2}$, la Potestad de Policía ${ }^{3}$ y el Derecho de Propiedad.

\footnotetext{
${ }^{1}$ No pretendemos hacer un debate lingüístico sobre si la traducción literal del concepto es expropiación regulatoria o regulación expropiatoria. Simplemente, utilizamos esta última en cuanto resulta más claro afirmar que es la regulación la que expropia, en vez que sea la expropiación la que regula.

${ }^{2}$ En cuanto al dominio eminente del Estado, el poder de la administración para expropiar un bien privado para un uso público permisible se le ha considerado en Estados Unidos como un atributo del Estado Nacional y los Estados federales. Este reconocimiento proviene de Kohl v/s United States (91 U.S. 1987 pág. 470), de 1875, caso en que por primera vez se usó el término “dominio eminente". Una definición sencilla y clara del dominio eminente parece ser la de Bond, al señalar que es el derecho del Estado, mediante su organización ordinaria, a reafirmar (reassert), sea temporal o permanentemente, su dominio sobre cualquier porción del suelo del Estado, debido a la necesidad o bien público. BOND (1998) p. 8. Este parece haber sido acuñado en 1625 por el escolástico holandés Hugo Grocio y desarrollado en ese país por diversos filósofos del derecho natural. ROHAN (1994) p. 876. En efecto, los tribunales norteamericanos a menudo explican el dominio eminente en referencia a los principios de derecho natural hasta el período posguerra civil. En Inglaterra y Estados Unidos se considera como una importante fuente de la teoría del dominio eminente la derivada de John Locke en relación a la delegación que hace el pueblo al Poder Legislativo. Locke equipara este poder a la facultad que tiene el Estado para cobrar impuestos. LOCKE (1960) p. 378.

${ }^{3}$ El juez supremo William Brennan está asociado al debate sobre la expropiación regulatoria primordialmente por su apoyo a las restricciones del poder de policía en numerosos fallos, afirmando que "las regulaciones del poder de policía, tales como los planes reguladores y otras restricciones del uso del suelo, pueden destruir el uso y el goce de la propiedad en orden a promover el bien público, de manera tan efectiva como una sentencia condenatoria formal o la invasión física de la propiedad" (San Diego Gas \& Electric Co. v. City of San Diego. 450 U.S. (1981) p. 621 (voto de minoría). La legitimidad subyacente al poder de policía es raramente discutida. Epstein, tal vez el teórico libertario de los derechos de propiedad, ha sostenido en su obra principal que "el poder de policía es completamente congruente con la teoría de Locke del Estado, que requiere que los individuos abandonen el estado de naturaleza pura con el objeto de obtener paz y seguridad contra las posibles agresiones de sus vecinos. Si los individuos pueden justificar el uso de la fuerza contra sus vecinos, del mismo modo puede el estado actuar en su nombre". EPSTEIN (1992) p. 108. La expansiva noción del poder de policía prevaleció en Estados Unidos durante la década del veinte y del treinta del siglo recién pasado, y es hoy por hoy mucho más controversial.
} 
¿Cuándo entonces debiera un sector determinado de la población soportar el costo de una regulación cuyos beneficios son aprovechados por la sociedad como un todo? Al perfilar el concepto de regulación expropiatoria, un punto conveniente de partida resulta ser el examen de una cuestión próxima: el derecho del Estado al dominio eminente. Cuando el Estado necesita una determinada propiedad privada para el uso público, manifiesta con claridad su intención, gravando una propiedad específica, y pagando posteriormente al ex propietario una "justa compensación”. De manera habitual o típica, el asunto clave en el uso estatal de dominio eminente es lo que constituye la justa compensación ${ }^{4}$.

Algunas de estas acciones del Estado no "sancionan" o afectan formalmente a una propiedad mediante el uso de dominio eminente. Pero mediante la utilización de una restricción severa del uso de dicha propiedad, deja al dueño en la misma posición jurídica descrita. En ciertas circunstancias, los tribunales norteamericanos han declarado a dichas acciones como regulaciones expropiatorias conocidas como regulatory takings ${ }^{5}$, puesto que han tenido los mismos efectos que el ejercicio del dominio eminente, y requiere, como consecuencia, que el Estado indemnice al dueño de la propiedad ${ }^{6}$.

\section{ORIGEN DE LA JURISPRUDENCIA DE REGULACIÓN EXPROPIATORIA}

El término regulación expropiatoria parece -a primeras luces- contradictorio toda vez que una regulación válida ejercida en virtud del poder de policía no es una expropiación, y que, por otra parte, una regulación inválida no puede ser catalogada de expropiación. La regulación expropiatoria se enmarca en la aseveración que señala que el actuar de la Administración que pretenda ser una regulación emanada de la Potestad de Policía, en realidad constituye una expropiación implícita. Por esto, "La garantía de la Quinta Enmienda está diseñada para prohibir al Estado de forzar a unos pocos a soportar individualmente las cargas públicas, las cuales en justicia y equidad, deben ser soportadas por el pueblo como un todo" 7 .

\footnotetext{
${ }^{4} \mathrm{El}$ argumento no es vago. De no pagar el Estado lo debido, existen poderosas razones para que no existan incentivos para las personas en invertir o adquirir bienes raíces, con las nefastas consecuencias que ello implica. POSNER (2003) p. 56.

${ }^{5}$ Como ya afirmamos, y sin perjuicio de esta observación más bien lógica, existe otra de carácter semántico, en cuanto el término debiera ser regulación expropiatoria. En este mismo sentido, EAGLE (1996) p. 3.

${ }^{6}$ De esta manera, los propietarios que creen que una regulación estatal ha efectivamente "expropiado" su dominio, pueden interponer una demanda contra el Estado por atentar contra la Quinta Enmienda. Ello, en un proceso conocido como "inverse condemnation action".

7 En efecto, quizás no existan palabras más citadas que las de este fallo de 1960 (364 U.S. (1960), p. 49) en juicios de expropiación. La frase corresponde al voto de mayoría redactado por el juez supremo Hugo Black en Armstrong v/s United States: los demandantes obtuvieron una sentencia favorable y el Estado fue condenado a pagar las deudas con los proveedores de un astillero, luego que este fuera expropiado. La utilización de este fallo ha sido unánime. El supremo Antonin Scalia citó dicha sentencia en uno de los casos más importantes de la expropiación regulatoria, Nollan v. California Coastal Commission, en 1987. Su usual oponente, el supremo William Brennan también empleó la cita en otra sentencia de importancia, San Diego Gas v. San Diego, de 1981. En definitiva, todos aspiraban a este ideal de "equidad y justicia".
} 
Pero dicho ideal, por más plausible que sea, debe ser trabajado con algo más de detalle y precisión, con el objeto de que verdaderamente tenga algún significado, trabajo al cual se ha dedicado gran parte de la doctrina norteamericana, sin poder evitar destacar el inconmensurable y macizo aporte que la Escuela del Análisis Económico del Derecho ha realizado en esta área ${ }^{8}$. Resulta evidente, entonces, que la problemática de la regulación expropiatoria va más allá que su análisis puramente procedimental y formal. Es conocido que en los sistemas jurídicos anglosajones el Derecho está configurado en gran medida por el antecedente jurisprudencial. Por ello, el estudio de la evolución de la jurisprudencia sobre la regulación expropiatoria resulta esencial para cualquier análisis que se pretenda hacer de ella. La evolución de los conceptos y su análisis resulta fascinante y llena de elementos jurídicos que enriquecen el debate. En esta área, el derecho norteamericano nos nutre fértilmente de fuentes para su análisis, por lo que intentaremos presentarlos de la manera más precisa posible 9 . A fin de cuentas, la regulación expropiatoria es una creación jurisprudencial ${ }^{10}$.

\footnotetext{
${ }^{8}$ El tema ha sido objeto de varios estudios académicos, en los que destacan dos grandes teóricos: Frank Michelman, profesor de la Universidad de Harvard, escribió un artículo en 1967 denominado "Propiedad, utilidad y equidad: comentarios en los fundamentos éticos del Derecho a la justa compensación”. El pensamiento esgrimido en dicho artículo ha sido objeto de cierto debate sobre el tema de la expropiación por más de un cuarto de siglo. Pero el académico de más renombre en esta área es sin duda Richard EPSTEIN, profesor de la Universidad de Chicago. Siendo uno de los intelectuales más citados, su influyente libro, Expropiación. Propiedad Privada y el Poder del Dominio Eminente-cuya última edición es de 1992, pero cuyas raíces se remontan a 1968-, ha sido utilizado como un texto base en la mayoría de las facultades de Derecho de Estados Unidos. Junto con lo anterior, debemos señalar que el primer artículo de importancia que trató el tema de la regulación expropiatoria fue el del connotado Joseph L. SAX, profesor de la Universidad de Michigan, cuyo artículo de 1964, publicado en The Harvard Law Review, Vol. 77. 701, (1964), pp. 717-729, y posteriormente modificado en 1971, publicado en The Yale Law Journal, Vol. 81, $N^{\circ} 2$ (Dec. 1971), marcaron el primer hito académico en materia de la regulación expropiatoria.

${ }^{9}$ En Chile, como señala Fermandois, "Pese a que se trata este de un antiguo problema del derecho público, se encuentra en estado doctrinariamente virgen (...) con la academia iuspublicista nacional en profunda deuda, salvo escasas excepciones". FERMANDOIS (2005) p. 21.

${ }^{10}$ El concepto de expropiación implícita resulta medianamente claro desde 1872, año en el cual se falló el caso Pumpelly v. Green Bay Co. La yuxtaposición de las palabras "expropiación" y "regulatoria" data -al menos- de la opinión del juez supremo Holmes en Pennsylvania Coal v/s Mahon. Sin embargo, el término "expropiación regulatoria" aparece originalmente en casos federales y estatales publicados desde el final de la década de 1970. Fue utilizado por primera vez en un fallo de la Corte Suprema en 1981, en el voto de disidencia redactado por el supremo Brennan en San Diego Gas \& Electric Company v/s City of San Diego.

Solo tres años antes de este fallo, Brennan redactó el voto de mayoría en otro caso importante dentro de la jurisprudencia de la regulación expropiatoria: Penn Central Transportation Co. v/s City of New York. En este caso se rechazó la aplicación de cualquier parámetro objetivo a la regulación de zonas urbanas. Aun así, la legitimación del concepto de regulación expropiatoria fue preservado en la observación de Brennan que afirma que "no abrazamos la proposición que sostiene que una expropiación no puede ocurrir a menos que la Administración haya transferido control físico sobre una porción de un predio". Desde este punto en adelante, la popularidad del término regulación expropiatoria creció rápidamente. De hecho, durante 1992 el término fue utilizado en al menos 36 casos federales, 45 casos estatales y en 25 artículos de revistas de derecho y otras 152 publicaciones. Ver CARLTON (1992) p. 12.
} 


\subsection{Pennsylvania COAL V/S MaHON (1922)}

Con toda tranquilidad podríamos afirmar que se trata del "Madison v/s Marbury"11 de la regulación expropiatoria. Pennsylvania Coal v/s Mahon ${ }^{12}$ es el primer y más citado caso de la Corte Suprema de Estados Unidos referido a la regulación expropiatoria. Los hechos son los siguientes.

Los trabajos de minería subterránea de carbón en Scranton, en el Estado de Pennsylvania, se iniciaron en 1887 a través de la empresa Pennsylvania Coal Co. En ese año, los derechos sobre los predios superficiales (sobre el yacimiento) fueron transferidos al padre de la Sra. Mahon. El acuerdo reservaba específicamente los derechos sobre el carbón subterráneo a la Pennsylvania Coal Co. En 1921 el Estado de Pennsylvania dictó la Ley Kohler, en virtud de la cual se prohibía la actividad minera de depósitos de carbón bajo la superficie de un predio que perteneciera a un tercero, siempre y cuando causara perjuicios a numerosos usos superficiales, incluyendo carreteras, fábricas, tiendas, colegios, iglesias y otros. La ley tenía como objetivo presionar a las empresas mineras a contribuir con otra ley dictada ese mismo año con el objeto de liberarlas de la responsabilidad civil por daños superficiales a cambio de una suma equivalente al $2 \%$ al precio de mercado de su mineral. El dinero sería destinado a crear un fondo estatal que pagaría por esos daños superficiales. En septiembre de 1921, la empresa notificó a la Sra. Mahon que iniciaría la explotación minera bajo su propiedad, a lo que ella contestó con una demanda invocando la citada ley. El tribunal de primera instancia falló a favor de la empresa, pero dicho fallo fue revocado por la Corte Suprema del Estado de Pennsylvania. La minera apeló ante la Corte Suprema de Estados Unidos alegando que dicha ley constituía una expropiación inconstitucional de la propiedad. El máximo tribunal acogió la demanda, en un fallo redactado por el juez supremo Oliver Wendell Holmes.

\footnotetext{
11 Para muchos, el fallo que dio origen al control de la constitucionalidad de las leyes. En 1801, el presidente Adams fue sucedido por el presidente Jefferson. Antes de dejar el cargo, Adams dejó realizados numerosos nombramientos judiciales que la nueva Administración no cursó. Uno de los afectados, Marbury, requirió a la Corte Suprema (en virtud de una ley de 1789) para que ordenara al secretario de Justicia (Madison) cursar el nombramiento. La Corte Suprema resolvió que ella no podía conocer el caso porque la Constitución establecía que solo era tribunal de apelación. La clave del fallo Marbury con Madison, redactado por el propio presidente de la Corte Suprema de la época, juez John Marshall, radica en que por una parte afirma la supremacía de la Constitución sobre las leyes, y, por otra, la obligación de los tribunales de justicia de asegurar dicha supremacía. Respecto de la supremacía constitucional, el fallo señala: "Los poderes legislativos son definidos y limitados; y para que esos limites no puedan confundirse $u$ olvidarse, la Constitución es una constitución escrita. ¿Con qué finalidad se limitarian los poderes y con qué propósito se habrian puesto esas limitaciones por escrito si esos límites pudieran, en cualquiera ocasión, ser sobrepasados por las personas mismas a quienes la Constitución intenta constreñir? ... Es demasiado claro para que se pueda discutir que: o la Constitución está por encima de cualquiera norma legislativa que no está de acuerdo con ella, o el legislativo puede modificar la Constitución por una ley ordinaria. Entre esas dos alternativas no hay término medio. O la Constitución es una norma superior y suprema y no puede ser alterada por los medios ordinarios, o está al mismo nivel que las disposiciones legislativas ordinarias, y, como ellas, puede ser modificada cuando al legislativo le plazca alterarla. Si lo primero es verdadero, un acto legislativo contrario a la Constitución no es ley. Si lo segundo, entonces las constituciones escritas son absurdas tentativas de parte del pueblo para limitar ese poder que es ilimitado por naturaleza".

12260 U.S. (1922), p. 412.
} 
El pasaje más notable del citado fallo reza:

"La regla general es, al menos, que mientras la propiedad puede ser regulada a cierto punto, si esta regulación va demasiado lejos, será reconocida como una expropiación. (...) En general no es común que las desgracias del hombre o sus necesidades vayan a justificar que transfiera estos daños a los hombros de su vecino. Estamos en peligro si nos olvidamos que el fuerte deseo público de mejorar la condición pública no resulta suficiente para garantizar la obtención de este deseo, mediante un atajo distinto a la vía constitucional de pagar por ese cambio..."13.

Cabe hacer notar que el supremo Holmes no se refería a que la Ley Kohler fuera irracional: él concibió que cuando las calles comenzaran a caerse y hundirse por si mismas, existiría un costo público que justifica el uso del dominio eminente. Pero el simple traspaso de un test de racionalidad, o aun el análisis costo-beneficio a gran escala, no releva al Estado de su obligación de pagar en un juicio respectivo. Esta obligación no fluye desde el escepticismo de un tribunal acerca de la racionalidad de una ley, sino del sentimiento de injusticia de redistribuir los derechos de propiedad tiempo después de su establecimiento $^{14}$.

A pesar del voto de disidencia ${ }^{15}$, la relevancia de Pennsylvania Coal es innegable y sus efectos se proyectan hasta nuestros días ${ }^{16}$.

\section{UNA POSIBLE TEORÍA UNIFICADA PARA EXPLICAR LA REGULACIÓN EXPROPIATORIA}

\subsection{EN BÚSQUEDA DE UN PATRÓN EN LAS DECISIONES DE LA CORTE SUPREMA}

Desde Pennsylvania Coal -y especialmente desde 1978- la doctrina de la Corte Suprema ha sido zigzagueante en la aplicación de su doctrina. Desde su dictación, podemos destacar - al menos- una docena de fallos relevantes en materia de regulación expropiatoria.

En esta área, la doctrina se encuentra en completa dispersión: aquí no solo resulta problemático determinar una línea clara que permita definir cuándo ha ocurrido una

\footnotetext{
13260 U.S. (1922) p. 413.

14 Sin perjuicio de lo anterior parece curioso el análisis histórico, social, económico e institucional que hace Fischel al concluir que ni la ley ni el fallo trajeron beneficio alguno para Scranton. En este sentido plantea la "total irrelevancia del fallo". FISCHEL (1999), p. 35.

${ }^{15}$ La única disidencia presente en Pennsylvania Coal es representada por el supremo Louis Brandeis, que resulta ser casi tan famosa como el voto de Holmes. Brandeis argumenta que a favor de lo que ahora se conoce como excepción de daño: si el uso de un predio es en sí mismo nocivo, peligroso o causa un daño público, el legislador es libre de regular su uso sin compensación alguna, aun cuando el poder de policía pueda causar pérdidas en el propietario. El argumento sería usado numerosas veces en el futuro, con el objeto de justificar la acción administrativa.

16 Aun así, algunos integrantes de la Corte Suprema de los Estados Unidos, como Stevens, ha revelado en sus fallos una total hostilidad hacia la doctrina de la regulación expropiatoria, que emerge de su visión hacia este caso. Por eso, para Stevens, Pennsylvania Coal es solo una opinión o un consejo y no verdadera jurisprudencia, en el sentido que tiene esta en el derecho anglosajón.
} 
expropiación, sino que su doctrina es tan confusa que resulta más un estorbo que una ayuda para los jueces que deben conocer de dichos casos. Para la gran mayoría de la doctrina el panorama no resulta más alentador ${ }^{17}$.

Dada la completa amalgama de definiciones del derecho de propiedad y sus conflictivas reglas para decidir cuándo nos encontramos frente a una expropiación, no existe manera de determinar con certeza cómo la Corte analizaría un caso determinado basándonos únicamente en su propia doctrina sobre este tema. A pesar de esta confusión doctrinaria, frecuentemente se puede predecir el resultado al que la Corte llegará en casos de expropiación, o la menos se puede anticipar si la Corte declarará que existió una expropiación. Esto sugiere la existencia de algún patrón subyacente en las decisiones de la Corte bajo la racionalidad articulada de estos casos: algunos autores sugieren que existen jueces supremos que son los que en definitiva resuelven los casos, descansando en su sentido de justicia cuando ha ocurrido una expropiación que merezca ser indemnizada, aun cuando los exámenes vigentes de expropiación de la Corte no apunten directamente al tema de la justicia o la equidad.

Los trabajos más importantes de los catedráticos norteamericanos apuntan a buscar entonces un grupo de principios que explicarían la gama completa de casos en que el tema de la regulación expropiatoria hubiera sido alegado: casos en que el Estado hubiera ejercitado formalmente su potestad dominio eminente, casos en que el Estado hubiera promulgado una normativa que se aplique al particular, y casos en que el Estado hubiere tomado acción física (como inundar el predio del privado). Una descripción unificada de cuándo nos encontramos frente a una expropiación, debe apuntar al menos a dos asuntos: el primero se refiere a cómo debemos definir el concepto de Propiedad ${ }^{18}$; en segundo lugar se debe distinguir entre privación indemnizable y no indemnizable de la propiedad. Con esto, intentaremos arrojar conclusiones que permitan identificar -ojalála presencia de ciertos principios que permitan revelar la existencia o inexistencia de una regulación expropiatoria, y que, por lo tanto, deba ser indemnizada en derecho.

Sin perjuicio de ser de conocimiento común entre los juristas norteamericanos que dicho Tribunal no ha proporcionado una línea definitoria de cuándo ha ocurrido una regulación expropiatoria ${ }^{19}$, también es conocido que la doctrina de la Corte proporciona un notable lineamiento de cuándo la Corte encontrará que ha ocurrido una expropiación $^{20}$.

\footnotetext{
${ }^{17}$ Ver Peterson (1989) p. 1341.

18 Para los sistemas continentales, dicha preocupación podría resultar inoficiosa, en consideración de que la gran mayoría de los códigos civiles entregan definiciones del concepto de Propiedad, de manera similares a lo establecido en el Código Civil chileno en el Artículo 582.

${ }^{19} \mathrm{La}$ Corte misma ha confirmado que ella no ha sido capaz de proporcionar criterios guía para determinar la ocurrencia de una expropiación regulatoria. V. gr. Loretto v/s Teleprompter Manhattan CATV Corp. 485 U.S. 419, 426 (1982) y anteriormente en Penn. Cent. Tranp. Co. v/s New York City, 438 U.S. 104, 124 (1978).

20 Para algunos autores, "la situación es aún más grave, puesto que no solo estaría en juego la definición de qué es lo que constituye una expropiación regulatoria, sino que se encontraría en abierta indefinición conceptos aún más gravitantes y fundacionales como el derecho de Propiedad. En este sentido, resalta el hecho que en constantes fallos, el concepto de Propiedad no ha sido solo divergente, sino que, en el algunos casos, abiertamente opuesto". PETERSON (1989) p. 1303.
} 
Aún peor, cuando algunos autores han podido extraer ideas y protoprincipios de estos fallos, estos ni siquiera se han puesto de acuerdo entre sí, respecto de cuáles y cuántos serían estos principios ${ }^{21}$.

Como consecuencia de lo anterior, la Corte ha expuesto al menos cuatro distintos juicios para determinar cuándo ha ocurrido una regulación expropiatoria. Quizás el único denominador común resulta el hecho que en todos estos casos la Corte ha señalado que en última instancia el factor decisivo es si en "justicia y equidad" corresponde una compensación económica causada por perjuicios derivados de una regulación estatal. No obstante, la Corte ha aportado poco y nada en explicar cómo su actual procedimiento se las arregla con el tema de la justicia.

Resulta imposible determinar si ha ocurrido una expropiación sin determinar previamente si el Estado ha privado al particular de algún tipo de propiedad: si no ocurre esto último, simplemente no hay compensación que deba ser pagada.

Desgraciadamente, la Corte Suprema norteamericana no ha otorgado un concepto unívoco sobre lo que considera propiedad. Con todo, la definición de relevant property resulta significativa cuando se trata de determinar la medida de la justa compensación, desde que la Corte generalmente echa mano del justo valor de mercado del predio expropiado $^{22}$.

La Corte ha enfocado el problema desde múltiples perspectivas. Analizaremos ahora las más relevantes, que apuntan a resolver finalmente el tema de ¿qué es lo que debe ser indemnizado?, ¿qué debe considerarse como propiedad expropiada, y por lo tanto indemnizable en derecho?23.

\section{a. Propiedad como cosa tangible}

A menudo, la Corte define propiedad en términos de ser una cosa tangible. En algunas oportunidades esa cosa tangible ha sido la cosa en su todo. Por ejemplo, en uno de los casos más conocidos en materia de regulación expropiatoria, Penn Central Station Co. v/s New York City ${ }^{24}$, los demandantes argumentaron que habían sido privados del

${ }^{21}$ Uno de los autores que ha buscado dichos principios es el profesor Frank Michelman, especialmente en MiCHELMAN (1987) pp. 1600-1622.

22 Uno de los casos que grafican esta postura es Kirby Forest Industries v/s United States, 467 U.S. 1, 10 1984), donde se entendió por justa compensación "el justo valor de mercado de la propiedad a la fecha de su apropiación por parte del ente administrativo".

23 Gran parte de este análisis ha sido desarrollado con mayor complejidad por muchos autores norteamericanos, en especial Andrea Peterson, William Sax y William Fischell, ya citados.

24438 U.S. (1978) p. 104. En 1968 se designó al terminal ferroviario de Penn Central en Nueva York (construido en 1913) como un "hito de la ciudad", por la New York City Landmarks Preservation Commission. Esto significaba que la Penn Central Transportation Company mantuviera las características arquitectónicas exteriores y de sus reparaciones del edificio terminal. Si la empresa deseaba hacer cambios, debía obtenerse un permiso que permitiera su alteración en que se especificara que dichos arreglos no afectarían la arquitectura del terminal, o debía obtener un certificado mediante el cual podía transferir los derecho de desarrollo, en el evento que no pudiera desarrollar el terminal de la manera permitida por el plan regulador. Ese mismo año, con el propósito de aumentar sus ingresos, se firmó un arriendo por 50 años renovables con una empresa británica para construir un edificio de oficinas sobre el terminal. Luego de una considerable negociación con la New York City Landmarks Preservation Commission, la empresa 
espacio aéreo sobre el terminal de Grand Central, en la ciudad de Nueva York, desde que la Administración les había denegado el permiso para construir un edificio de oficinas sobre el mencionado terminal.

La Corte, no obstante, insistió que debía analizarse el caso considerando "la propiedad como un todo", incluyendo el espacio aéreo, pues afirmó que la unidad relevante de propiedad como "el predio que ha sido designado como un lugar histórico". El Tribunal, finalmente, centró su análisis sobre la base de los efectos de la negativa administrativa que recaerían sobre la propiedad considerada como un todo ${ }^{25}$.

En una segunda acepción de propiedad como cosa tangible, la Corte ha definido propiedad como "el predio completo" en casos que ha recurrido al llamado "juicio de no viabilidad económica"26. Cuando la Corte se pregunta si una regulación relativa al uso del suelo que ha sido impugnada, deniega a sus propietarios "de todo uso económicamente viable" de su propiedad, se ha perfilado a la "propiedad" como el predio en sí mismo ${ }^{27}$. En estos casos ha rehusado el tratar una porción de predio completo como la "unidad geográfica relevante".

No obstante la Corte ha insistido que esta "unidad de la propiedad" es la totalidad de la cosa tangible, ha definido en ciertas oportunidades a esta unidad relevante como una porción fisica identificable de una cosa tangible mayor. Esto resultó cierto, por ejem-

de ferrocarriles presentó un proyecto para un edificio de 55 pisos, el cual indubitablemente debía sujetarse a todas las normas de construcción y de plan regulador, junto a las relacionadas con la preservación histórica. La Comisión rechazó la solicitud de Penn Central en orden a que "el edificio 55 sobre la fachada "Beaux-Art" del terminal no parecía otra cosa que una broma estética". La empresa apeló al tribunal local de Nueva York, el cual determinó que la decisión de la Comisión constituía una expropiación, fijando audiencia para la solicitud de Penn Central con el objeto de un reparo a sus perjuicios. Cuando el caso llegó a la Corte Suprema, no dejó de ser polémico. El caso no solo era glamoroso y simbólico, sino de una gran importancia práctica. Tal como explicó el juez supremo William Brennan, redactor del voto de mayoría, la ordenanza de Nueva York era "común” y su método de preservación no consistía en la apropiación de propiedades históricas, sino en involucrar al público titular de las decisiones sobre el uso del suelo que afectaban dicha propiedad. En el fondo, existía el temor que de aceptar los argumentos de Penn Central, "invalidaría no solo la ley de Nueva York, sino toda la legislación comparativa sobre hitos urbanos de la Nación”, por ese motivo la Corte rechazó la demanda de la empresa. Quizás uno de los aspectos más importantes de Penn Central es el intento por determinar un "fórmula" que sirviera para muchos otros casos, lo cual estuvo lejos de ser conseguido en esta oportunidad. Sin embargo, se buscó establecer tres factores que se pudieran utilizar uniformemente. Las conclusiones no se hicieron esperar por parte de la doctrina: Se criticó por el hecho de intentar crear argumentos con el objeto de suavizar la condena y "balancear los intereses". La retórica de balancear los intereses de las partes, puede hacer que la decisión de un caso sea razonable pero no mecánicamente obligatoria. Mas cuando se sondea bajo la superficie de estos argumentos que emplean deliberadamente esta retórica -la del balance de intereses-, a menudo se puede encontrar que no existe fondo para el uso de la palabra "balance". En estos casos, el arte de balancear permanece oscuro a pesar de su importancia central en la propia postura del Tribunal, la cual termina siendo una herramienta atractiva para quienes no pueden articular las bases de sus sentencias, o que simplemente carecen de confianza en sus deliberaciones. Tal vez, una vez más, "el poderoso deseo público" no alivia las necesidades de una justa compensación.

25 La Corte determinó que no hubo expropiación, basada en otros elementos de su "juicio de tres factores", que explicaremos en detalle más adelante.

${ }^{26} \mathrm{El}$ ejemplo recurrente de este concepto se extrae de Hodel v/s Indiana, 452 U.S. (1981) p. 314.

27 Un caso en que trató este concepto fue Williamson County Regional Planning Common v/s Hamilton Bank, 473 U.S. (1985) p. 172. 
plo para "Loretto v/s Telempromter Manhattan CATV Corp." "28. En este caso, la Corte adoptó una regla per se, que cualquier ocupación física y permanente de un propiedad autorizada por la Administración es una expropiación, y por lo tanto una ley que obliga a los propietarios permitir la instalaciones de TV cable en sus edificios se traduce como efecto en una expropiación. En definitiva, la Corte concluyó que la Administración había expropiado una pequeña área ocupada efectivamente por las instalaciones de TV cable.

En Loretto, la Corte ni siquiera intentó explicar cómo pudo considerar que la perturbación de una parte mínima del edificio era una privación o menoscabo de la "propiedad", cuando en Penn Central y en otros casos había insistido en que la única propiedad relevante para efectos de la regulación expropiatoria es "el predio en su todo".

\section{b. Propiedad como derechos económicamente valiosos creados por el derecho positivo}

Históricamente, la Corte ha rechazado considerar derechos subjetivos preexistentes relativos a bienes raíces como "propiedad relevante". En Penn Central29, por ejemplo, la Corte rehusó tratar tanto el espacio aéreo sobre el terminal como el derecho legal preexistente a desarrollar en este espacio aéreo como la "propiedad relevante" 30 .

\footnotetext{
28458 U.S. (1982) p. 419. En este caso, la Corte Suprema determinó que en virtud de una ley de Nueva York, la cual requería que los propietarios de residenciales permitieran la instalación de servicios de televisión por cable, se debía pagar a los usuarios una compensación nominal de un dólar. La historia es la siguiente: La nueva residente de uno de estos edificios, la señora Loretto, se enteró del cableado existente cuando adquirió su departamento en un pequeño edificio de la ciudad y demandó daños y perjuicios en virtud de que la instalación del cableado del edificio, sin su consentimiento, constituía una regulación expropiatoria. Con anterioridad a 1973, fecha en que la normativa fue aprobada, las compañías de cable acostumbraban pagar una compensación a los dueños de los edificios en la suma correspondiente al 5\% de las utilidades brutas correspondientes al edificio respectivo. La Corte de Apelaciones de Nueva York dictaminó que la televisión por cable tenía importantes beneficios comunitarios y educacionales, y que ninguno de ellos producían un impacto económico excesivo en la señora Loretto y tampoco constituían una privación de sus expectativas razonables de retorno de la inversión. El redactor del fallo de mayoría, el supremo Marshall, concluyó que la ocupación permanente y física autorizada por la Administración es una expropiación sin importar los intereses públicos que esta pueda servir. De este modo cualquier ocupación física, por pequeña que sea, puede invocar la cláusula de expropiación. El voto de minoría redactado por el juez Blackmun presentó importantes interrogantes no respondidas por la opinión de Marshall; esta se concentró en el hecho que en Penn Central y otros casos sobre regulación expropiatoria se han basado en fundamentos flexibles y por lo tanto la afirmación del juez Marshall constituía un curioso anacronismo. En conclusión, dado el examen per se de Loretto, se puede afirmar categóricamente la eliminación del balance requerido bajo Penn Central, por lo cual no es sorpresa que muchos demandantes intentaron deshacerse de este examen e insertar demandas que incluían "una expropiación física con el objeto de obtener la declaración de una expropiación regulatoria”.

29438 U.S. (1982) p. 419.

30 Otro tanto sucedió en Keystone Bituminous Coal Association v/s DeBenedictis, 480 U.S. 1987, p. 470, donde la Corte no solo rechazó la noción relativa a que el carbón que no puede ser explotado era "la propiedad" en cuestión, sino que también estableció que el caso no podía ser analizado como una expropiación de un derecho legal preexistente a la explotación minera en la manera que ocasionaba daños.
} 


\section{c. Propiedad como derecho adquirido económicamente valioso, creado por el derecho positivo}

En un sinnúmero de casos de expropiación, la Corte ha dicho que a menos que un derecho creado por legislación positiva sea un "derecho adquirido", no se debe entender como "propiedad" para efectos de la expropiación.

Lo anterior descansa sobre la premisa de que si el Estado otorga a una persona un derecho por ley, normalmente retendrá la potestad para cambiar la ley con el objeto de servir al Bien Común, y por ende, no ha ocurrido expropiación alguna por haber ejercido el Estado su potestad, aun cuando el cambio o modificación de la ley elimine el derecho de esa persona bajo la legislación previa. Tal como la Corte ha afirmado, dicha persona no ha perdido ningún derecho adquirido ${ }^{31}$.

De este modo, la Corte Suprema, en lo que a expropiación se refiere, deja la definición de Derecho de Propiedad en un completo desparramo. No obstante, el Tribunal no parece particularmente perturbado o consciente de la inconsistencia en sus definiciones de Propiedad. Por lo general, utiliza una de sus definiciones de propiedad sin conocimiento de que ha sido usada en otros casos sobre expropiación. De hecho, la Corte ha dado más de una definición de propiedad en un mismo asunto ${ }^{32}$.

\subsection{LOS EXÁMENES DE LA CORTE SUPREMA PARA DETERMINAR SI HA OCURRIDO}

O NO UNA EXPROPIACIÓN

La confusión, ya vista en la definición de propiedad de la Corte, es solo sobrepasada por la que existe al explicar cuándo ha ocurrido una regulación expropiatoria. A menudo, la Corte afirma que el quid del asunto en un caso de expropiación resulta ser si -en justicia- se requiere que una compensación sea pagada. Aun así, raramente se refiere a la justicia en una caso de expropiación. Muy por el contrario, y de conformidad a la gran parte de la doctrina norteamericana, la Corte aplica uno de los cuatro "exámenes"

31 Esto se vio claramente en Bowen v/s Public Agencies Oppossed to Social Security Entrapment, donde la Corte sostuvo que no existió expropiación, puesto que los derechos alegados por los demandantes no eran adquiridos: El Estado de California firmó un acuerdo con el Ministerio de Salud en el que el Estado se comprometía a participar en el Sistema de Seguridad Social. El acuerdo contenía una cláusula de término similar al derecho de renuncia al Sistema de Seguridad Social, con una notificación de 2 años de anticipación. Luego que este derecho a ponerle fin al contrato fuera eliminado por un cambio en la legislación, los demandantes argumentaron que la cláusula de terminación del contrato era un derecho de propiedad valioso que había sido quitado sin justa compensación. La Corte respondió que ninguna expropiación había ocurrido, puesto que los demandantes no eran titulares de un derecho adquirido, y por lo tanto, sobre la cláusula en particular. La Corte consideró que el caso era sencillo, puesto que el Congreso había reservado "expresamente" las potestades de enmendar o derogar cualquier cláusula de una ley anterior. En otros casos, la Corte determinó que la Administración había reservado “implícitamente” la potestad de cambiar la ley. En Bowen v/s Gilliard, y en Bowen v/s Public Agencies, la Corte -al igual que en muchos otros referidos a expropiación y derecho adquiridos- concluyó que la legislación común solo articula la política actual y no persigue trabar a la Administración en el futuro. Así, no crea "derechos adquiridos". PETERSON (1989) p. 1313.

32 V. gr., en Williamson County Regional Planning v/s Hamilton Bank. 473 U.S. (1985) p. 172, donde la Corte concluyó que un caso de expropiación no debía ser visto, sin importar si la propiedad expropiada fuera vista como el predio mismo, o como el derecho adquirido de los demandantes a construir. 
que tiene para determinar si una acción estatal distinta al ejercicio formal del dominio eminente constituye un expropiación. Estos son: a) El examen Penn Central de tres factores; b) el examen Agins de dos partes; c) el examen de uso económicamente no viable (que es la segunda parte del examen Agins) y la regla per se de Loretto.

Ahora bien, según muchos autores el uso de estos tests ha sido muy insatisfactorio: en primer lugar resulta muy difícil determinar cuál de los exámenes utilizará la Corte en un caso particular; además, si cualquiera de ellos es utilizado, existe considerable incertidumbre de qué es lo que significa cada examen.

Estos exámenes son también insatisfactorios en términos de principios, por cuanto la Corte no ha explicado cómo es que abordan la pregunta sobre cuándo "la equidad" requerirá que un determinado caso sea indemnizado, o de por qué esa pregunta debe ser respondida utilizando un número de exámenes diferentes y lógicamente incompatibles. Veamos de qué se tratan estos exámenes desarrollados jurisprudencialmente por la Corte Suprema norteamericana.

\subsubsection{Examen Penn Central de tres factores}

Debemos remontarnos al año 1978 para ver los orígenes de este método analítico. Desde esta fecha la Corte ha utilizado este sistema, debido a fue ese el año en que se ventiló el caso Penn Central Transportation Co. v/s New York City, ya citado ${ }^{33}$. En esa oportunidad, la Corte reconoció que en decisiones anteriores sobre expropiaciones había actuado esencialmente ad hoc, caso a caso, y que había intentado dotarse de cierta estructura para futuras decisiones, mediante la identificación de tres factores que consideraron particularmente significantes en la determinación de cuándo una acción administrativa constituía una regulación expropiatoria. Esos factores son el carácter de la acción administrativa, la extensión de esa interferencia con las expectativas razonables del particular, y el impacto económico de la acción administrativa sobre el particular.

No obstante, estos tres factores no han entregado mucha "estructura" en términos del análisis que buscaba la Corte. En primer lugar, el máximo Tribunal ha definido cada factor en un sinnúmero de acepciones, sin advertir las alternancias en las definiciones. Luego, resulta difícil predecir qué peso le otorgará la Corte a cada factor. Por último, no resulta claro cuándo el examen de Penn Central, a diferencia de otros exámenes de expropiaciones, debe aplicarse. El examen de la aplicación de cada factor ilustrarán estas dificultades.

\section{a. El carácter de la acción administrativa}

La Corte usualmente utiliza este factor para preguntarse si la Administración ha invadido físicamente la propiedad tangible del particular o bien si ha autorizado a un tercero para hacerlo. El Tribunal ha sostenido que en dichos casos resulta más probable encontrar una verdadera expropiación, considerando para ello que una invasión física es "una restricción del derecho de propiedad de un carácter inusualmente serio" ${ }^{4}$. Debe

33483 U.S. (1978) p. 104.

${ }^{34}$ La cita pertenece a Loretto v/s Teleprompter Manhattan CATV Corp., ya mencionado. 
agregarse que la Corte determinó que en el caso que la ocupación física sea permanente, "el carácter de la acción administrativa" no es solo un factor importante para resolver si la acción constituye una expropiación, sino que de hecho es el factor determinante.

Así, en otro fallo, Hodel v/s Irving ${ }^{35}$, un caso en que una regulación estatal impedía heredar ciertos paños pequeños de terrenos, la Corte nuevamente concluyó lo mismo, pero en este caso enfatizó que "el derecho de transmitir una propiedad, a la familia de uno en particular, ha sido parte del sistema legal anglosajón desde el derecho feudal."

Ahora bien, la Corte ha usado "el carácter de la acción administrativa" en sentidos diametralmente opuestos. En Keystone Bituminous Coal Association v/s DeBenedictis $(1987)^{36}$ la Corte se enfocó más en la justificación de la acción administrativa que en su carácter. En este caso, la Corte utilizó el primer factor del examen Penn Cenral para preguntarse si la Administración buscaba prohibir un determinado uso del suelo que sería indudablemente perjudicial para las personas; al hacerlo, la Corte trasladó el foco de discusión de tratar de determinar si la Administración había impuesto un serio perjuicio al demandante, a preguntarse si la acción de la Administración había sido justificada o no. La Corte no explicó en su fallo por qué el enfoque de su cuestionamiento bajo el factor del "carácter de la acción administrativa" había sido sustituido tan dramáticamente.

\section{b. La extensión de la interferencia en relación a las expectativas económicas razonables de la inversión del particular.}

Este segundo factor del examen Penn Central también ha sido interpretado de variadas formas. Cuando la Corte discute este factor, normalmente está considerando si la razonabilidad del reclamo del particular -respecto de su detrimento económicodescansa en una expectativa de que el Estado no habría actuado como lo hizo, esto es, que no hubiera privado de la propiedad al dueño. Sin embargo, en otras oportunidades, se ha enfocado en si la normativa cuestionada permite o no al particular realizar algún uso razonable de su recurso tangible. En una tercera acepción de este factor, la Corte equipara "expectativas razonables" con "Propiedad". Aún más, a veces se utiliza este factor como el decisivo, y a veces como el menos importante.

35481 U.S. (1987) p. 704.

${ }^{36}$ Este resulta ser el único caso en que la Corte no continuó con su transformación. Muy por el contrario, dio su respaldo a una normativa (Pennsylvania Subsidence Act), la cual se asemejaba sorprendentemente a la Ley Kohler en cuya virtud se dictó el famoso Pennsylvania Coal. Tal como lo señalábamos en el párrafo anterior, la citada ley ordenó que la empresa minera Keystone dejara pilares de carbón sin explotar, de manera de proteger a la superficie de un colapso. De modo similar, la compañía llegó hasta la Corte suprema imputando que la ley era expropiatoria. Cuando el caso llegó al Tribunal Supremo, el voto de mayoría fue redactado por el juez Stevens, el cual afirmó que la ley cuestionada "no involucra un balance entre los intereses económicos privados de las compañías de las empresas de carbón contra los intereses privados de los propietarios de predios superficiales, sino que tiene por objeto minimizar las externalidades negativas en ciertas áreas", lo que en definitiva se tradujo en el rechazo de la demanda de la compañía carbonífera. En relación con este fallo gran parte de la doctrina ha afirmado que los efectos de los diferentes fallos entre Pennsylvania Coal y Keystone revelan las diferencias de criterio dentro de la Corte. En efecto, el voto de disidencia redactado por los jueces Rehnquist, Powel, O'Connor y Scalia afirma que "por 65 años Pennsylvania Coal ha sido el fundamento de la jurisprudencia relativa a expropiación regulatoria de esta Corte, y que las diferencias entre este caso y Keystone, rozan en lo trivial”. 
Para despejar un poco la discusión, convengamos que en la mayoría de los casos la Corte concluye que no se han interferido las expectativas razonables, desde que la acción del Estado fuere previsible. El caso más evidente de previsibilidad -entendido como un conocimiento cierto y comprobable- resulta ser cuando el particular sabía efectivamente que la Administración realizaría la determinada acción expropiatoria.

Cuando la acción administrativa envuelve un cambio en la normativa, la Corte frecuentemente opina que este cambio en la normativa es previsible dada la historia de la regulación de la actividad industrial ${ }^{37}$. En otros casos, la Corte ha concluido que la Administración -expresa o implícitamente- ha reservado la potestad para modificar una normativa. En todo caso, el segundo factor del examen Penn Central, no ha servido para despejar la incógnita de cuándo se trata de una expropiación.

En cuanto a la "razonabilidad" de la expectativa, la Corte pareciera considerar la razonabilidad de la misma al momento que la inversión fue realizada. En otras oportunidades, la Corte ha usado el término de este factor para preguntarse si la normativa discutida permite al particular reclamante algún uso razonable de la propiedad tangible, como por ejemplo sucedió en el mismísimo Penn Central. Para no detener ahí la discusión, la Corte pareciera equiparar el concepto de expectativa razonable de retribución de la inversión al de Propiedad ${ }^{38}$.

Bajo el examen de Penn Central, no queda del todo claro cuál es el rol que cumple la "interferencia con las expectativas razonables" en el análisis de la Corte. Cuando el Tribunal utiliza esta expresión para preguntarse si es per se un prerrequisito para que exista una expropiación, ¿es por si solo suficiente para establecer que una expropiación ha ocurrido, o debe la Corte considerar que existen también otros dos factores en este examen, antes de determinar que nos encontramos frente a una expropiación?

Las respuestas a estas preguntas pueden variar de caso en caso. A veces, el Tribunal utiliza este factor para preguntarse si el Estado permite al particular realizar cualquier uso razonable de la propiedad. En este caso, la Corte pareciera decir que si algún uso razonable es permitido, entonces no existe expropiación. No obstante, cuando la Corte equipara expectativa razonable con Propiedad, la Corte se está preguntando si el Estado ha privado al particular de cualquier tipo de propiedad, y no si esa privación constituye una expropiación que deba ser indemnizada: la interferencia con las expectativas razonables serían un prerrequisito para establecer que nos encontramos frente a una expropiación, si es que la propiedad está definida en términos de una expectativa razonable.

37 Este concepto presenta un desarrollo notable en Conally v/s Pension Benefit Guaranty Corp (475 U.S. (1986) p. 211.

38 En Williamson County Regional Planning Commission v/s Hamilton Bank, este último alegó expropiación desde el momento que el Estado había desconocido un derecho adquirido a desarrollar sus terrenos de un determinado modo. La Corte se refirió a esta controversia desde el punto de vista de los derechos adquiridos como desde el de las expectativas razonables de retribución de la inversión, puesto que la Corte sugirió que este interés en las expectativas era la unidad relevante de propiedad, desde el momento en que el Banco basó su argumento en la pérdida de su derecho adquirido a construir. De este modo, no siempre resulta clarificador cuando la Corte se refiere a expectativas y derecho adquiridos, esté considerando si los demandantes fueron despojados de su propiedad o de si considera que tal despojo constituye una expropiación que deba ser indemnizada, lo que resulta ser dos cosas distintas. 


\section{c. El impacto económico de una acción estatal}

Tal como señalamos, el factor final de este examen constituye el impacto económico de la acción del Estado en el particular. Una vez más, la Corte no ha sido clara ni consistente en definir este factor. La noción que reconoce que ha ocurrido una expropiación cuando la regulación disminuye notablemente el valor de una cosa, se originó en Pennsylvania Coal v/s Mahon ${ }^{39}$, ya citado. Este es el célebre caso de una compañía minera que reclamó contra la llamada Ley Kohler (que prohibía la actividad minera que causaba efectos secundarios respecto de ciertas estructuras aun cuando la compañía minera había adquirido previamente el derecho legal a ocasionar tales efectos secundarios), pues constituía una expropiación.

Cuando la Corte se refirió a la "disminución de valor" no se refería a cuán grande había sido la pérdida en dólares. En efecto, la Corte había calificado de expropiación en un sinnúmero de casos donde la pérdida, medida en dólares, había sido apreciablemente poca $^{40}$. Muy por el contrario, el Tribunal consideró la proporción del valor original del terreno que había sido destruido como una consecuencia de la regulación. El Tribunal no ha tomado una posición consistente en cuanto al rol que la "disminución del valor" juega en el análisis expropiatorio: en Penn Central la Corte se cuestionó si la expropiación no dependía en cuanto la normativa había disminuido el valor del predio, sino que si esta normativa permitía al particular el uso de su predio en algún propósito "económicamente viable". De lo anterior podemos desprender que la Corte parece estar diciendo que una disminución severa en el valor no establece per se una expropiación en cuanto el terreno pueda ser utilizado mediante algún uso económicamente viable. Aun así, en Keystone no distinguió entre la disminución del valor y "el uso no económicamente viable", sino que aparece equiparándolos al afirmar que "nuestro examen para una regulación expropiatoria nos exige comparar el valor que ha sido tomado de la propiedad con el valor que permanece en dicha propiedad" 41 .

En un caso u otro, resulta poco claro si la Corte visualiza el impacto económico como un examen independiente para establecer si ha ocurrido una expropiación o si simplemente se trata de un factor a considerar. El lenguaje de la Corte sugiere que, en estos casos, si la acción administrativa ha disminuido suficientemente el valor de la propiedad relevante, ha ocurrido entonces una expropiación basada únicamente en este factor ${ }^{42}$. Por otra parte, en algunas situaciones la Corte ha fallado sentenciando que no ha existido expropiación aun cuando la normativa impugnada ha privado al particular de todo uso económicamente viable para su propiedad.

\subsubsection{Examen Agins de dos partes}

A pesar que el examen Penn Central ha constituido el marco básico para el análisis sobre muchísimos casos desde 1978 hasta la fecha, la Corte ha descansado

\footnotetext{
39260 U.S. (1922) p. 339.

40 Ver por ejemplo en Hodel v/s Irving, 481 U.S. (1987) p. 704, en especial el voto fundamentado del juez supremo Stevens.

41480 U.S. (1987) p. 471
} 
también en otros exámenes para determinar la ocurrencia de una expropiación. En Agins v/s City of Tiburon ${ }^{43}$ decidió sobre la base de otros esquemas solo dos años después que Penn Central.

Agins fue probablemente lo más lejos que llegó la Corte Suprema en sus intentos por aplicar una fórmula de balance. La Corte rechazó la demanda por unanimidad basada principalmente en el hecho que el Tribunal californiano había sostenido que a Agins aún le quedaba algo de valor. Adicionalmente, este caso levantó otros problemas relativos al federalismo y al sistema constitucional ya que el Tribunal Supremo pretendía ahora que las Cortes estatales evitaran la eliminación de los requisitos indemnizatorios de la Quinta Enmienda. En el citado fallo, la Corte creó este examen bajo el cual la acción administrativa que alcanza a cualquiera de las dos partes de aquel, es considerada

42 Idéntica afirmación se realiza en Keystone 480 U.S. (1987), p. 472.

43447 U.S. (1980) p. 255. Este caso se originó en el Estado de California. La ciudad de Tiburón es un suburbio de alrededor de seis mil personas a siete millas al norte de San Francisco. Situado en una península montañosa que mira a la bahía de San Francisco, muchos residentes gozan de una excelente vista a la ciudad y al vecino puente Golden Gate. Uno de los factores de conveniencia de la ciudad de Tiburón está en que el ingreso medio por hogar en 1980 era cerca del doble de la media del Estado de California, convirtiéndola en la comunidad más pudiente del área metropolitana de San Francisco. El valor medio de una propiedad en 1980 duplicaba también a la media estatal. También tenía (y aún tiene) una inusual gran cantidad de espacio abierto de propiedad privada para ser un suburbio ubicado convenientemente cerca del centro de un área metropolitana. Donald Agins, un dentista que residía en otra localidad, adquirió un sitio sin edificaciones en el borde del risco de Tiburón en el año 1968, en el cual deseaba construir viviendas para sí mismo y para otros. El patrón de desarrollo de Tiburón ha sido históricamente la construcción que va desde el fin de la península que mira hacia San Francisco, cubriendo tanto las tierras planas como el risco (el risco tiene el mismo largo que la península). La parte del risco que se inicia cerca de cien yardas al sudeste del predio de Agins ya estaba cubierto por un proyecto de desarrollo unifamiliar de alta densidad. Agins, por lo tanto, esperaba desarrollar un proyecto similar, de al menos veinte casas, en casi cinco acres. Tiburón tenía otros planes para el risco. Se contrató una consultora que en 1972 exploró las opciones con el objeto de preservar espacios abiertos. Dicha constructora recomendó la compra de gran parte de los terrenos que se encontraban a lo largo del risco incluyendo el predio del señor Agins. El concejo municipal autorizó la compra por 1.25 millón de dólares pagaderos en bonos con el objeto de adquirir el risco, decisión que fue aprobada por los votantes. El problema con la emisión de bonos de 1972 fue que la ciudad había subestimado el costo de adquisición de la propiedad. Todas las propiedades comenzaron a incrementar su valor de manera más rápida que la inflación. La ciudad abrió negociaciones con el doctor Agins según lo requerido por los estatutos del dominio eminente, pero estas no condujeron a ninguna parte. Comenzó entonces un juicio relativo al dominio eminente que luego la ciudad desistiría. Frustrados por su incapacidad de adquirir los terrenos, el concejo municipal decidió en 1973 negociar con Agins y otros propietarios de predios del risco de manera de poder reducir la densidad establecida para esa zona. La justificación de este proceder residía en una nueva ley estatal en virtud de la cual se requería a todas las comunidades la provisión de espacios abiertos. La ley también especificaba que, en cualquier caso, los derechos de propiedad privada debían ser respetados. Tiburón omitió este requisito. La modificación de las normas de constructibilidad en la propiedad de Agins y otros propietarios del risco permitió la construcción de viviendas unifamiliares, pero a densidades más bajas que las permitidas previamente en el área y que en muchas otras zonas de desarrollo de la comunidad. En la práctica, la ciudad trató de bloquear tanto desarrollo urbano en la zona como fuera posible en orden a mantener estos terrenos como espacio abierto. Agins interpuso su reclamo respecto de la mencionada ley ante la Corte de California y ante la Corte Suprema. La primera rechazó a la demanda en virtud de que la condena por daños cometidos en virtud de una regulación simplemente no estaba disponible en el Estado de California: esta Corte sostuvo que no existía expropiación en virtud de que aún quedaba algún valor en la propiedad de Agins y que por lo tanto este valor residual era suficiente para satisfacer el examen de balance creado en Penn Central. 
una expropiación. Lo curioso es que la Corte pareció no notar que este examen difería del realizado en Penn Central ${ }^{44}$.

En ciertas ocasiones pareciera que la Corte ha equiparado la primera parte de su examen con la mínima racionalidad que debe existir en las condiciones del debido proceso sustantivo, pero también ha usado la primera parte de este examen para determinar si el Estado está previniendo una conducta dañina. En otras oportunidades, la Corte ha usado la segunda parte del examen en conjunto con la primera. A su vez, también ha usado la segunda parte como la única necesaria para determinar si ha ocurrido una expropiación. Finalmente, en algunos pocos casos la Corte ha sugerido que aun cuando una normativa prive al propietario de cualquier uso económicamente viable de su predio, no necesariamente ha ocurrido una expropiación ${ }^{45}$.

Con el objeto de ilustrar estos puntos analizaremos en qué consiste cada una de las partes del examen de Agins. La primera parte de este examen nos ilustra que ha ocurrido una expropiación si la regulación que rige al predio no adelanta sustancialmente un legítimo interés estatal. Lo anterior aparece como un equivalente al patrón de mínima racionalidad del debido proceso sustantivo. No obstante, la Corte no explica por qué utilizaron esta materia -que dice relación con el debido proceso- para determinar si había ocurrido o no una expropiación.

En otro número de casos, la Suprema Corte omitió la primera parte de este examen sin explicación y simplemente afirmó que se trataba de una expropiación si la regulación del uso del predio denegaba al propietario de un uso económicamente viable de su propiedad. Posteriormente, en Keystone resucitó la primera parte del examen de Agins, sosteniendo que existe expropiación si la ley no adelanta sustancialmente un interés legitimo estatal o si deniega al propietario del uso económicamente viable de su predio.

Lo que cabe destacar de Keystone es que la Corte interpretó la primera parte de este examen de maneras distintas: tal como en Agins, lo equiparó con la racionalidad mínima del debido proceso sustantivo (preguntándose si la normativa había servido a un interés legitimo público), luego la Corte se preguntó si la Administración buscaba prevenir un uso dañino o nocivo del terreno: de este modo la Corte no solo se preguntó si la Administración promovía el Bien Común, sino que, además, en un modo particular prevenía una conducta dañina.

Finalmente, el Tribunal concluyó que la regulación estaba dirigida contra una actividad perniciosa. Bajo esta lógica se habría establecido que no ha ocurrido expropiación alguna. Sin embargo, bajo el examen Agins de dos partes, la Corte no podía concluir que no se trataba de una expropiación sin preguntarse si la normativa privaría a los particulares de cualquier uso económicamente viable de su tierra. De este modo la Corte terminó encontrando que no había existido expropiación únicamente porque el Estado estuviera previniendo una conducta dañina.

${ }^{44}$ En Agins, la Corte simplemente destacó que "ninguna regla precisa determina cuándo alguien ha sido privado de su propiedad".

45480 U.S. (1987) p. 256. 


\title{
3.2.3 Examen del uso económicamente inviable
}

La segunda parte del examen de Agins -el requisito que se refiere a que la regulación del uso de la propiedad no niegue a los propietarios todo uso económicamente viable de la propiedad- fue objeto de una referencia en Penn Central. En Agins la Corte terminó por incluir este comentario en la segunda parte de su nuevo examen.

En cierto número de casos de regulación expropiatoria, que siguieron a Agins y que precedieron a Keystone, la Corte estableció que el "único examen" para cuando una regulación del uso de la propiedad tenía como efecto una expropiación, era si la regulación denegaba a sus propietarios de todo uso económicamente viable de su predio. El único aviso claro que el examen de "la inviabilidad económica" sería aplicado como el único examen para expropiaciones formales, apareció en Hodel ${ }^{46}$. En ese caso, la Corte sostuvo que si la aplicación de un estatuto a una particular área del predio es tomada como una expropiación, la Corte estaba utilizando el examen de Penn Central. Pero resultó que el Tribunal encontró rápidamente que la acción estatal no era una expropiación bajo el examen de la inviabilidad económica. Para ilustrar este concepto nos remitiremos al voto de minoría de San Diego Gas \& Electric Co. v/s San Diego, donde el supremo Brennan, junto a otros tres jueces entendió por examen de inviabilidad económica:

\begin{abstract}
"Regulaciones de Policía como las ordenanzas de zona (planos reguladores) y otras restricciones del uso del suelo pueden destruir el uso y goce de la propiedad en orden a promover el Bien Común, tan efectivamente como una sentencia condenatoria formal o invasión física de la propiedad. Desde el punto de vista del propietario, importará poco si su predio resulta afectado por una condena judicial o inundado, o si resulta restringido por una regulación de usarlo en su Estado natural, si el efecto en todos estos casos es la privación de la misma de los beneficios del uso de ella"17.
\end{abstract}

\footnotetext{
46 Este resulta ser el menos bullado de los fallos sobre expropiación regulatoria dictados en 1987. Los legisladores del siglo XIX, que enmendaron la Constitución norteamericana, se preocuparon de que las tierras poseídas por indígenas dentro de sus reservaciones no fueran vendidas a terceros. En orden a prevenir dichas ventas, el Congreso impuso la prohibición a los indígenas para vender o dar en legado dichas tierras. Luego de varias generaciones, muchas de las reservaciones cuya propiedad pertenecía a indígenas se fragmentó en parcelas demasiado pequeñas. Estas parcelas eran tan reducidas y la propiedades eran tan fragmentadas que su utilización se hizo totalmente perjudicial desde un punto de vista económico. En 1983 se dictó una ley que permitió al Estado consolidar las parcelas altamente fraccionadas en la misma tribu respectiva. Pero dicha norma legal no tenía disposición alguna relativa a la indemnización para las más pequeñas de las parcelas, por la sencilla razón que los costos de transacción de hacerlo eran extremadamente altos en comparación con el valor de cada predio. La Corte Suprema, al conocer del caso, señaló que debía hacerse una compensación, en el entendido que el derecho de legar la propiedad, sin importar cuán mínimo sea su valor, es uno de los derechos constitucionalmente protegidos.

El tema central de este caso gira en torno al derecho de enajenación. La redactora del fallo, la jueza suprema O'Connor, hizo notar que era dudoso que los descendientes de alguno de los apelados tengan “expectativas de retorno de la inversión” como herencia. Aun así, la jueza consideró que la regulación era "extraordinaria", y que "se abrogaba el derecho de transmitir en cierto tipo de propiedad -los pequeños interese no divididos- a los herederos, sistema que se encuentra en nuestro sistema desde los tiempos feudales".

47450 U.S. (1981), p. 621.
} 
La Corte ha sugerido con frecuencia que una regulación que prive a su dueño de todo uso viablemente económico de su propiedad es necesariamente una expropiación. Ocasionalmente, sin embargo, la Corte ha sugerido que en ciertos casos el Estado puede justificar el privar al propietario de todo uso económicamente viable de su predio, que por equidad no requerirá del pago de una compensación. En First English Evangelical Lutheran Church v/s County of Los Angeles ${ }^{48}$ los propietarios alegaron expropiación al adoptar el condado de Los Angeles una ordenanza interina prohibiendo la construcción o reconstrucción de edificios en un área que fuera anegada por las aguas. Si los edificios de los demandantes fueran destruidos por anegamientos, y la ordenanza les prohibiera reconstruir estas estructuras, los afectados demandaron que mientras la ordenanza interina estuviera vigente, les privaba de todo uso económicamente viable de sus tierras. La Corte sugirió entonces que aun cuando la ordenanza les privaba de todo uso económicamente viable de las tierras, no necesariamente les afectaba una expropiación, desde que la ordenanza fue dictada como una medida de seguridad. Así, la Corte cambió de preguntarse qué es lo hecho por el Estado a los particulares, a preguntarse por qué había actuado el Estado.

\subsubsection{Regla de Loretto de "Ocupación física permanente" per se}

Quizás en la única área donde la Corte ha intentado proveer de una regla de línea clara, resulta ser en aquellas oportunidades cuando la administración ha invadido físicamente la propiedad (o "cualquier otra cosa tangible") del particular, o que ha autorizado a un tercero a hacerlo.

48482 U.S (1987). En 1957, la First English Evangelical Lutheran Church of Glendale adquirió una parcela de 21 acres en un cañón, y en una porción plana de 12 acres estableció un complejo que incluía dos comedores, dos quinchos y una capilla al aire libre, junto con otras instalaciones. En este lugar operaba "Lutherglen", un centro de campamentos usados para retiros y otras actividades recreacionales para niños discapacitados. En julio de 1977 un incendio quemó gran parte de los bosques de los cerros cercanos, creando una zona de peligro de alud, en al febrero de1978 se deslizó por las colinas destruyendo Lutherglen. En respuesta, la ciudad de Los Angeles creó un área provisoria de protección de aludes, mediante una ordenanza temporal, que prohibía la construcción y reconstrucción de edificios en una determinada área. La ordenanza, que conculcaba el derecho a reconstruir Lutherglen se hizo inmediatamente efectiva debido a que el condado determinó que dicha norma era necesaria para la inmediata preservación de la salud y la seguridad públicas. La iglesia demandó al Estado y al Distrito de control de aludes por los perjuicios causados por negligencia e inter alia su correspondiente indemnización. Esta demanda expropiatoria fue desechada por el tribunal local bajo el argumento que la demanda era improcedente, como consecuencia de la decisión de la Corte Suprema de California en Agins. La Corte de Apelaciones respectiva confirmó el fallo de primera instancia. Cuando el caso llegó a la Corte Suprema, el asunto fue tomado por su presidente, el juez Rehnquist, la cual rechazó lo fallado por la Corte californiana. En su opinión resultó esencial la idea que la ordenanza temporal de suelos no habría sido evacuada aun cuando hubiere atribuido al condado de Los Angeles un uso beneficioso de las tierras de la iglesia; de haberlo hecho, la ordenanza hubiera constituido evidentemente una expropiación. De este modo, el juez Rehnquist citó inmediatamente los casos en que la Suprema Corte ha restringido al Estado y a la autonomía local. Como consecuencia, la Corte Suprema sostuvo por un margen de seis votos contra tres que de existir expropiación la iglesia debía ser compensada monetariamente desde el momento en que la regulación ilegal se hizo efectiva. El caso bajó nuevamente al tribunal californiano y a su correspondiente apelación, el cual determinó que no existió expropiación alguna y que por lo tanto no era necesario indemnizar. 
El nombre de esta regla deriva del caso Loretto v/s Telepromter Manhattan CATV Corp., de 1982, donde la Corte introdujo la regla per se de que cualquier ocupación física permanente de la propiedad autorizada por el Estado constituía una expropiación. El estatuto u ordenanza general del Estado de Nueva York requería que dueños de edificios permitieran la instalación de equipos de TV cable, con el objeto de habilitar que su inquilinos recibieran televisión por cable y de manera de facilitar la conexión hacia otros edificios. El Tribunal aplicó la regla per se y calificó expropiación a la situación en que una compañía de cable, actuando bajo la autoridad del estatuto del Estado, instalara equipos de cable, en el techo, y costados de edificios de dueños de edificios o pensiones.

A la Corte no le importó si "la acción importaba un importante beneficio o servicio público o bien si solo tenía un impacto económico mínimo”. Así, en Loretto la Corte se enfocó no en la justificación estatal de su acción, sino exclusivamente en lo que el Estado había hecho contra el particular. La Corte consideró el daño causado al privado, particularmente serio, no por la cantidad de dinero envuelta en el asunto, sino por la "intrusión" de la acción estatal.

La regla de Loretto distinguió entre invasiones físicas temporales e invasiones físicas permanentes. Cabe hacer notar que la Corte destacó que "no toda invasión física constituye una expropiación: las limitaciones temporales deben ser objeto de procesos más complejos para determinar si son o no expropiaciones" ${ }^{49}$, queriendo decir con esto que para estos últimos casos debía recurrir al examen de tres factores de Penn Central.

La Corte descubrió, finalmente, que con la instalación de equipos de cable se habían "apropiado" permanentemente del espacio destinado al techo de la construcción, así como de parte del costado del mismo, y eso constituía una expropiación. La Corte también afirmó que la regla Loretto se aplicaba aun cuando el dueño de la propiedad pudiera evitar la ocupación física, mediante la renuncia o negativa de arrendar la propiedad ${ }^{50}$.

\section{APLICACIÓN DE LA DOCTRINA DE LA CORTE SUPREMA EN MATERIA DE REGULACIÓN EXPROPIATORIA}

Otro fallo significativo en materia de regulación fue Nollan, de 1987, el que marcó el comienzo del cuestionamiento de la Corte Suprema respecto de la relación entre los medios y los fines de la Administración, y cuya demanda fue acogida por la Suprema Corte ${ }^{51}$. El caso trataba de una familia que se le exigía entregar un pedazo de

\footnotetext{
49458 U.S. (1982) p. 435.

50458 U.S. (1982) p. 428.

51 Los Nollan eran dueños de un predio con vista al mar en la costa californiana que se encontraba entre parques públicos a mitad de milla de estos en sus deslindes norte y sur. El lote contenía un pequeño y dilapidado bungalow, el cual deseaban reemplazar por una casa de tres dormitorios similar a otras construidas en el área. Los Nollan solicitaron el permiso correspondiente a la Comisión de Costa, la cual tenía la autoridad legal para imponer condiciones de acceso público en los permisos que otorgaba con el objeto de reemplazar las viviendas unifamiliares existentes, solo donde el proyecto propuesto pudiere producir un impacto adverso en el acceso público al mar. La comisión otorgó el permiso bajo la condición de que los Nollan constituyeran una servidumbre pública en la zona que mediaba entre la línea de altas mareas y el
} 
su propiedad costera para una servidumbre pública como condición para construir su vivienda. El Tribunal asumió que los Nollan, habiendo comprado su predio de sus anteriores propietarios, tenían el derecho a construir en él si es que no causaban un daño público con tal acto. La Corte rechazó el argumento de que los requerimientos de acceso público fueron diseñados para deshacer el perjuicio que los Nollan hubieran causado mediante el bloqueo de la vista hacia la playa. Finalmente, rechazaron la petición porque el público se beneficiaría del paso a través de la propiedad de los Nollan, y la equidad no requiere el pago de una compensación.

En un tribunal inferior, donde se hubiera ventilado el caso Nollan usando las doctrinas preexistentes de la Corte en materia de expropiación, no habrían analizado el caso de la misma manera. En efecto, resulta difícil para un juez predecir qué definición de propiedad y cuál examen sobre expropiación habría hecho la Corte ${ }^{52}$. A mayor abundamiento, algunos de los caminos que hubiera tomado el juez podrían haber llevado a concluir que no hubo expropiación en Nollan. No obstante, este caso jurisprudencial nos provee de una ilustración de un problema fundamental con la actual doctrina sobre expropiación de la Corte Suprema de EE.UU.: la doctrina no resulta útil para decidir si ha existido o no expropiación, porque no apunta hacia el problema de la equidad que -según la Corte nos afirma- debe estar en cada caso sobre expropiación.

muro de la casa, de manera de permitir el paso público a través de la arena seca conectando los parques públicos ubicados al sur y al norte de la propiedad (en otras palabras, la servidumbre debía correr de manera paralela al mar). Los Nollan interpusieron un recurso administrativo en contra de la comisión, la cual luego de algunas audiencias confirmó su posición bajo el supuesto que las medidas adicionales de la casa a construir contribuirían al desarrollo de una pared de estructuras residenciales, las cuales "prohibirían psicológicamente al público de realizar un recorrido costero del cual tienen derecho a visitar". La Corte superior del Estado de California rechazó la condición bajo el argumento que el proyecto de los Nollan no impedía el acceso al mar, pero la Corte de Apelaciones respectiva revirtió el fallo sosteniendo que la casa reconstruida contribuiría indirectamente a la necesidad de acceso público como parte de un proceso acumulativo de desarrollo de la línea costera, aun cuando no causare una necesidad por mayor acceso directo.

52 Finalmente, la Corte Suprema apoyó a los Nollan. El fallo fue redactado por el juez supremo Scalia (textualista y originalista), el cual sostuvo que la servidumbre exigida por la comisión no mitigaría el supuesto bloqueo de vista. Por esta razón, la condición de acceso a la playa carecía de nexo con el propósito original de la regulación. Como resultado, la servidumbre constituiría una expropiación para uso público cuya indemnización debía ser pagada. Recordando el lenguaje utilizado en Loretto, no se disputaba en este caso que hubiera existido "una invasión física de la propiedad". Por tal motivo la Corte resolvió que la compensación no podía ser en forma de excepción a otra regulación a menos que existiera un nexo entre la regulación exceptuada y el propósito de la servidumbre. Nollan resulta ser el más problemático de los casos de expropiación en términos de acomodarla bajo las reglas que los abogados utilizan para asesorar a sus clientes. Este caso se enmarca bajo el comportamiento de la Corte Suprema en el sentido que esta intenta demostrar que existen ciertos esquemas regulatorios tan cercanos en espíritu al dominio eminente, que deben ser tratados como expropiaciones. Este fallo fue continuamente citado por otros casos posteriores. Se ha afirmado que "Nollan nos enseña que la ciudad puede gravar constitucionalmente al demandante para recuperar los costos de externalidades negativas que el incremento de sus actividades económicas puedan causar: sin la demostración de dichas externalidades, la condición en que la ciudad basa sus permisos de construcción es simple extorsión, tal vez no sea necesario para la ciudad el demostrar una correspondencia exacta y matemática entre el peso de la prueba y la carga pública, a pesar de que resulta claro que cualquier impuesto claramente desproporcionado correría en contra de la Quinta Enmienda”. 


\subsection{LAS NUEVAS LECCIONES DE CASOS RECIENTES}

Los recientes Lucas $^{53}$ de 1992 y Tahoe del 2001 trajeron nuevos ángulos al debate. Para algunos, muchos de los cambios producidos en las sentencias de la Corte Suprema norteamericana son tributarias de la influencia del Law and Economics ${ }^{54}$. La decisión de la Corte Suprema en Lucas, que rechazó seis a tres la apelación interpuesta por los demandantes, afirmó que la moratoria fuera una expropiación per se bajo las perspectiva de Lucas y First English. Sobre este punto vale la pena rescatar el análisis que presenta el profesor Roberts ${ }^{55}$. En él señala que First English fue un caso sobre la satisfacción que recibe el demandante por el daño que le han causado. En primer lugar, la doctrina considera que en First English la Corte sostuvo que lo debido en un caso de regulación expropiatoria era la indemnización. Las medidas judiciales o declaratorias no resultan adecuadas para mitigar los efectos de una expropiación que ya ha ocurrido ${ }^{56}$. En First English, la compensación a

53 El trasfondo histórico de Lucas se remonta a 1986, cuando David H. Lucas, un inversionista inmobiliario, adquirió dos lotes residenciales en la costa de la Isla de las Palmas en el Estado de Carolina del Sur. Lucas participó en la subdivisión de los paños en los cuales se encontraban los lotes y los compró por $\$ 975.000$ dólares para sí mismo por cuanto el proyecto aún necesitaba completarse. Lucas viviría en una de las viviendas que se construirían en uno de los lotes, mientras que la otra sería para la reventa. Estos estaban separadas por un lote perteneciente a un tercero. Al tiempo que Lucas adquirió los lotes, no existían restricciones administrativas que perjudicaran a lotes de su pretendido propósito. Poco después, sin embargo, una nueva ley estatal, la BMA, prohibió toda construcción en el borde de la playa, con excepción de "ciertas mejoras no habitables, $v$. gr., pasarelas construidas de madera no superiores a 6 pies de ancho, y pequeñas plataformas de madera no superiores a 144 pies cuadrados. Lucas demandó en sede local, con la concesión que la BMA era un ejercicio válido de la potestad o poder de policía, pero conservando que dicha norma constituía una completa extinción del valor de su propiedad, calificándola de expropiatoria. El tribunal de primera instancia acogió el hecho que la propiedad del Sr. Lucas había sido expropiada y ordenó una inmediata compensación. En una instancia superior de apelación, la Corte del Estado de Carolina del Sur revirtió el fallo, sosteniendo que la BMA era una ley válida y apropiada que preserva las playas de Carolina del Sur. Luego que Lucas se defendiera en la Corte de Apelaciones de Estado, pero antes del fallo, la BMA fue enmendada permitiendo que el Consejo de Costas otorgara permisos especiales para la construcción de la zona costera, incluyendo el área donde Lucas tenía su propiedad. Con esto se pretendió que, de llevarse el caso a la Corte Suprema, la ley no pareciera tan severa. Por ello sus redactores utilizaron el vocablo "prevención de daño" con sospechosa frecuencia: era evidente que se querían hacer valer de la "excepción de daño" que había sido utilizada años atrás en el ya visto Keystone. Por otra parte, si la ley pretendía prevenir un daño, resultaba obvio que si se reconocía el hecho de que el propietario había sido privado completamente del valor de la propiedad, por el hecho de prevenir un mal público, no había indemnización que pagar. La Corte Suprema no aceptó este argumento y acogió la demanda, revirtiendo el fallo de la Corte estatal. El fallo fue redactado por Scalia, para quien la eliminación total del valor de la propiedad sin compensación alguna debía ser apoyada por algo más que una declaración legislativa de daño. La opinión disidente, liderada por Blackmun, se apoyó en el argumento que afirma que a través de los años la Corte siempre ha declarado que el ejercicio del poder de policía no puede constituir una expropiación. De cualquier modo, en un juicio posterior, que terminó por transacción entre las partes, el Estado de Carolina del Sur terminó por comprarle la propiedad al Sr. Lucas.

${ }^{54}$ Interesante en este aspecto resulta en análisis en la doctrina nacional de MARMOLEJO (2004) p. 34.

55482 U.S. 304 (1987).

56 Por esa razón, en la sentencia de First English se afirma que "Simplemente sostenemos que cuando las actividades del Estado han causado una expropiación de la cosa, ninguna acción subsecuente del Estado puede relevarlo del deber de proveer una compensación". En el voto de mayoría, el juez supremo Stevens nos recuerda que First English era "indubitablemente" un caso sobre la compensación que recibe el demandante por el daño que le han causado, en que se resolvió sobre el mérito del proceso, en especial de cuándo ocurrió la expropiación. El hecho que First English involucraba una moratoria era irrelevante para esa 
ser pagada solo resulta operativa luego que un tribunal determine que una regulación ha afectado a una expropiación, es decir, las expropiaciones temporales que no permiten del todo el uso de la cosa no son diferentes a una expropiación permanente, seguido por el argumento de que las privaciones temporales de todo uso del bien, como la moratoria, son expropiaciones sin más. El argumento se vio apoyado por el hecho que la regulación discutida en First English fue una moratoria. En Tahoe-Sierra la Corte rechazó dicho argumento. En Tahoe-Sierra ${ }^{57}$, del 2001, acabó también con la lectura que se tenía de las

postura, ya que se sugiere que la mera denegación del uso total de la propiedad por un período de tiempo no constituía en sí misma una expropiación. De este modo, el juez supremo Stevens apunta en First English que los propietarios de un bien deben tolerar demoras normales en los procesos de obtención de permisos para el uso del suelo, sin esperar por ello una compensación.

57 La Tahoe Regional Planning Compact ordenó a la Tahoe Regional Planning Agency, o TRPA, un ente regulatorio en materia de planificación del desarrollo inmobiliario de la zona de Tahoe, ubicada a las orillas del lago del mismo nombre, en la frontera de los estados de California y Nevada, a desarrollar un plan regulador con el objeto de revertir el deterioro de las aguas del lago Tahoe. En agosto de 1981, la TRPA dictó una norma moratoria que congelaba la nuevas actividades de desarrollo en ciertos predios mientras desarrollaba el proceso de creación de un nuevo plan. La moratoria permanecería vigente hasta que un nuevo plan regulador regional fuera dictado. La TRPA no finalizó el plan en el plazo esperado, llevándola a dictar una nueva moratoria en agosto de 1983. Esta duró hasta abril de 1984, fecha en que se dictó el plan definitivo. El Estado de California se opuso al nuevo plan, el día en que este fue acordado, aduciendo que no era lo suficientemente riguroso en la protección del lago. La Corte de distrito federal apoyó la implementación del plan. Esta orden judicial tuvo vigencia hasta 1987, fecha en que el nuevo plan regional fue promulgado. En el intertanto, dos meses después de la adopción del plan en 1984, un grupo de terratenientes (que serían los demandantes en el caso Tahoe-Sierra) interpusieron una demanda en contra de la TRPA, solicitando que la moratoria de 32 meses (que corrió desde agosto de 1981 hasta abril de 1984, y que el plan de 1984) fueran considerados como expropiatorios de sus predios, bajo la cláusula de expropiación de la Quinta Enmienda constitucional, y que por lo tanto tenían derecho a una indemnización. Al examinar los actos de la TRPA al establecer la moratoria y al desarrollar el Plan, el tribunal federal de distrito determinó que la intensa actividad de desarrollo en el área del lago Tahoe y la sensibilidad ecológica de este, hacian del plan de la TRPA una tarea tremendamente compleja. El tribunal estableció que la TRPA había actuado razonablemente. Los propietarios recurrieron a la Corte Suprema para que intercediera en este caso. La Corte solo accedió a pronunciarse sobre si la Corte de Apelaciones había determinado apropiadamente si la moratoria temporal en el desarrollo de los predios había constituido o no una expropiación que requiera indemnización bajo la cláusula de expropiación de la Quinta Enmienda. En una decisión de 6 votos contra 3, la Corte Suprema confirmó la sentencia de la Corte de Apelaciones, concluyendo que la moratoria no constituía una expropiación. Es importante hacer notar que la primera de las preguntas sugiere que los recurrentes no se encontraban cómodos con la posición que debían asumir en relación con la decisión de la Corte de Apelaciones. El argumento presentado fue que la moratoria era categóricamente una expropiación, y no una moratoria que podía constituir una expropiación. Aun así, fue este posterior argumento el presentado ante la Corte Suprema, presumiblemente descansando en la visión que el juez Kozonski tenía de la opinión de la Corte de Apelaciones, en el sentido de tomar la postura que la moratoria nunca podía constituir expropiación. La verdad es que jamás ningún tribunal aseveró tal cosa: lo señalado por la Corte de Apelaciones es que resulta poco probable que un tribunal alguna vez estuviera de acuerdo con tal proposición. Aun así, si se responde la primera de las interrogantes, negativamente, como probablemente hubieran querido los peticionarios, hubieran quedado abandonados, puesto que el señalar que la moratoria pueda ser una expropiación no ayuda a los terratenientes, ya que el tribunal de distrito resolvió que los actos de la Agencia habían sido razonables. Al revertir el fallo del tribunal de distrito, la Corte de Apelaciones señaló que los propietarios solo alegaron una expropiación categórica. La Corte rechazó el argumento de que los 32 meses de moratoria debían ser extraídos del conjunto de derechos de propiedad, y debía ser visto separadamente con el propósito de determinar el impacto económico de la ordenanza. Más detalles en RoberTs (2002) p. 8. 
decisiones involucradas en Lucas casi 10 años antes. En este último, la Corte sostuvo que cuando una regulación privaba al propietario de todo uso económicamente viable, existe expropiación, a menos que el Estado puede probar que la regulación no hace otra cosa que restringir el uso lo que los tribunales del Estado pueden hacer bajo los principios subyacentes de las leyes sobre propiedad o de daño público ${ }^{58}$. Ignorando, o tratando como irrelevante el hecho que Lucas involucraba una restricción permanente, los propietarios argumentaron que la moratoria que deniega todo uso económicamente viable es una expropiación, como en Lucas. Tahoe-Sierra nos afirma que la permanencia de la regulación en Lucas fue crítica respecto de la premisa que afirma que la cláusula de expropiación protege contra la "enajenación del valor" 59 . Por esta razón, el solo hecho que uno se vea retardado por un período de tiempo, no se eleva a un nivel mayor de severidad. Las regulaciones son solo para ser convertidas en expropiaciones constructivas en instancias donde son verdaderamente excesivas, y -en estos casos-Lucas y Tahoe-Sierra serían extremadamente excepcionales. En otras palabras, cualquier cosa inferior a la "eliminación completa del valor" o a una "pérdida total", afirma la Corte en Lucas, requeriría el tipo de análisis esbozado en Penn Central 60 .

De este modo, la Corte rechaza utilizar formulas per se en las expropiaciones parciales. Tahoe-Sierra limita a Lucas a regulaciones permanentes que priven de todo el valor de la propiedad ${ }^{61}$. En este caso, y empalmando con lo afirmado anteriormente, la pregunta específica del factor Penn Central se refiere ahora a que la carga de la prueba para los demandantes en Tahoe-Sierra consistía en demostrar que la sola dictación de la moratoria constituía una expropiación. La nula flexibilidad del argumento llevaba a que si cualquier moratoria (de 10 minutos a 10 años) era una expropiación, terminaba por condenar esta postura ${ }^{62}$. Por otra parte, la idea que existía una diferencia constitucional entre una ley que prohibía el uso hasta que se sometiera al proceso de obtención de un permiso para el desarrollo del terreno, que podía o no resultar, y una ley que prohibiera el uso hasta que la Administración pudiera desarrollar un plan de cómo debe ser usado el suelo, era un argumento difícil de aceptar por parte del tribunal. A fin de cuentas, Tahoe-Sierra termina por auspiciar la regulación territorial ${ }^{63}$

En Tahoe-Sierra, la Corte le entrega un fuerte apoyo a la regla de "la parte como un todo". La determinación clave es saber si se utiliza la categórica regla de Lucas o el examen multifactorial de Penn Central, resulta ser la unidad de propiedad relevante para medir la pérdida económica. Escogiendo solo la porción de tierra afectada por la regulación, incrementa las perspectivas de una total disminución en el precio.

\footnotetext{
58505 U.S. p. 1027.

59 ROBERTS (2002) p. 9.

60122 S. Ct. p. 1483.

${ }^{61}$ El voto de minoría redactado por los supremos Rehnquist y Scalia estuvo por acoger la solicitud. El argumento se basaba en que las expropiaciones regulatorias producen iguales efectos que las expropiaciones físicas.

${ }^{62}$ La cita corresponde a una trascripción del argumento oral, 2002 WL 43288, p. 12.

${ }^{63}$ El fallo señala que "Los controles interinos son una herramienta esencial de un desarrollo exitoso". 122

S. CT. (2002) p. 1487.
} 
Años después de Penn Central, la Corte continúa utilizando la regla de la porción como el todo ${ }^{64}$. Ahora, tan solo a cuatro año de haber declarado esta "disconformidad", la Corte apoya fuertemente la aproximación de "la parte como un todo" en TahoeSierra ${ }^{65}$, citando los argumentos de Penn Central en el sentido que "la jurisprudencia sobre expropiación no divide una unidad del bien en segmentos"66. La Corte rechazó una indemnización temporal pedida por los propietarios que argumentaron que habían sufrido una pérdida por 32 meses ${ }^{67}$. El haber aceptado esta indemnización hubiera significado que cualquier atraso es un pérdida total, invocando la regla de Lucas $^{68}$.

\section{CONCLUSIONES}

Han transcurrido más de dos siglos desde la dictación de la Constitución norteamericana, y prácticamente lo mismo desde Madison v/s Marbury. Sin embargo, este cuerpo normativo constitucional sigue ampliando su aplicación y renovando su vigencia doctrinal. El objeto de este trabajo fue realizar un acercamiento al estudio de los fallos dictados por la Corte Suprema, constatando la variedad de interpretaciones - no siempre uniformes, pero innegablemente valiosas- como aporte doctrinal y práctico de cada uno de ellos. Por otro lado, observamos cómo la jurisprudencia ha construido el concepto de regulación expropiatoria, que no tiene otro fin que el de proteger a los ciudadanos de su propio gobierno, pero a la vez intentando trazar límites claros para delinear su aplicación.

El concepto de regulación expropiatoria va más allá que una simple construcción teórica: es una verdadera institución jurídica en que se articulan conceptos básicos del derecho privado como la Propiedad y la Libertad Económica, por una parte, y por la otra, principios fundacionales del derecho público como el Bien Común y la Potestad de Policía. Por esta razón nos pareció interesante su estudio, ya que a nuestro juicio traspasa las barreras del estudio tradicional del derecho público.

Una teoría unificada de regulación expropiatoria debiera proveer una base para distinguir entre privaciones de propiedad compensables (expropiaciones indemnizables) y privaciones de propiedad no compensables. Ninguna de las aproximaciones actuales de la Corte explican completamente lo que en el derecho norteamericano se conoce como el case law ${ }^{69}$. No se pueden explicar las decisiones de la Corte únicamente mediante el

${ }^{64}$ Este criterio se repitió en Keystone en 1987. La Corte puso una nota de duda acerca de la regla de la parte como un todo, cuando en Palazzolo $v / s$ Rhode Island se refirió a una nota a pie de página de Lucas como una indicación de su disconformidad con la lógica de "la parte como un todo". Pero desde Palazzolo no ha desafiado la aplicación de esta regla.

65122 S. CT. (2002) p. 1465.

66122 S. CT. (2002) p. 1481.

${ }^{67}$ El fallo mereció incluso comentarios por el célebre profesor Epstein al afirmar que "el sustentar el poder de la Administración para imponer esta moratoria en un nueva casa en construcción, le da luz verde a la Agencia como para dictar otros 2 años de moratoria”. EPSTEIn (2002) p. 32.

${ }_{68} \mathrm{Al}$ respecto parece interesante lo planteado con humor por KORDESH (1996) p. 232.

${ }^{69}$ Se entiende como precedente Jurisprudencial o Judicial a las Leyes y Principios de Derecho que tienen como base las sentencias judiciales dictadas por los jueces. MC GraW HiLl PUblishers (1998) p. 48. 
examen de la actuación del Estado contra el particular, sin consideración si se debe enfocar la severidad del daño causado o del carácter inusual del daño sufrido. Si se observa la justificación de la Administración para privar al particular de su propiedad, no es posible preguntarse únicamente si el Estado actuó para promover el Bien Común, desde que el Estado frecuentemente realiza expropiaciones indemnizables cuando -precisamente- promueve el Bien Común. Tampoco puede preguntarse acerca de si el Estado debiera prevenir un daño, ya que hay casos en que el este no previene dichos daños, pero aun así no se trata de expropiaciones. Sin embargo, se podría tal vez distinguir entre expropiaciones indemnizables y privaciones de propiedad no compensables, definiendo de manera más amplia la clase de casos en que la justificación del Estado para privar al particular de la propiedad estableciera que la equidad no requiere del pago de una compensación. Así, a pesar de que la Corte se pregunta frecuentemente si el particular descansó -económicamente- en la expectativa de que el Estado no habría actuado del modo en que lo hizo, en la mayoría de los casos dicha confianza no parece ser la llave para determinar la existencia de una expropiación.

La actual doctrina del Tribunal Supremo relativa a la regulación expropiatoria no provee de base alguna para determinar la existencia de una expropiación de esta clase, ya que esta ha utilizado demasiadas definiciones de propiedad y excesiva cantidad de exámenes para determinar si nos encontramos en presencia de una regulación expropiatoria. A pesar del caos de la actual doctrina, los resultados en los casos sobre expropiación de la Corte son sorprendentemente predecibles. Si, de hecho, existe un patrón para los casos sobre expropiación vistos por la Corte, debiéramos ser capaces de articular un grupo de principios que describan cuándo la Corte determinará la existencia de una regulación expropiatoria.

En parte de este trabajo hemos concluido que ciertos elementos de la actual doctrina expropiatoria de la Corte puede ser utilizada como base para la construcción de un camino coherente que sirva para determinar la existencia de una expropiación. Construyendo sobre ese análisis, se puede afirmar que el patrón evidente en la jurisprudencia puede ser explicada de mejor manera demostrando que la Corte determinará la existencia de una expropiación cada vez que el Estado fuerce intencionalmente al particular a entregar su propiedad, a menos que el legislador esté buscando la prevención o el castigo de una acción (u omisión) del particular en que crea que -razonablemente- el público considerará como un mal. Se concluye, entonces, que los casos de expropiación pueden ser mejor explicados mediante la utilización de una definición de propiedad consistente de dos partes. Primero, donde el particular posea la libertad para actuar de manera que le sea económicamente valioso para él, aun cuando esta libertad para actuar haya sido otorgada a dicho particular por el derecho positivo. En segundo lugar, el Estado puede reservarse el poder de cambiar la ley de un modo que altere este derecho. Si el Estado actúa dentro de este espectro de su poder reservado, no existe expropiación alguna.

Esta explicación no solo es válida para los resultados de la mayoría de los casos vistos por la Corte, sino que también sirve para muchas proposiciones generalmente aceptadas de cuándo ha existido una expropiación. Esto no hace que los casos futuros sean más sencillos de resolver, pero sí muestra el porqué algunos casos son relativamente 
fáciles de decidir y otros resultan tan complicados, ofreciendo un marco coherente para analizar los casos de regulación expropiatoria

Sin perjuicio de lo anterior, debemos hacer un comentario aparte respecto del novísimo Tahoe-Sierra. Este confirma lo que gran parte de la doctrina ${ }^{70}$ y los tribunales ${ }^{71}$ han dicho sobre la moratoria: no son expropiaciones per se. En este sentido, el fallo no sorprende. En otros casos sobre expropiación, como Nollan, la Corte ha adoptado argumentos basados en el tratamiento que -acorde al asunto- le dan la mayoría de los tribunales inferiores. En Tahoe-Sierra, la Corte cambió de opinión. El resultado, sin embargo no es una conclusión perdida. Por su parte, el fallo de First English contenía confusas y contradictorias argumentaciones acerca de las expropiaciones temporales. Mientras otros tribunales han evitado el error del juzgado de distrito en Tahoe-Sierra, es satisfactorio para el Derecho que la Corte Suprema de Estados Unidos haya tomado el asunto para resolverlo -al menos- con claridad.

No obstante la dispersión de la dogmática norteamericana, el grado de análisis y debate está a años luz del incipiente desarrollo de la doctrina y jurisprudencia nacionales donde los casos de regulación expropiatoria no abundan y su estudio académico es aún más ausente. El análisis de dicha teoría en nuestro país podrá ser objeto de un trabajo ulterior. Del mismo modo, las políticas públicas propuestas por los norteamericanos para resolver este tema, y gracias a la profundidad y seriedad de las ideas presentadas con el objetivo de crear un sistema indemnizatorio que resuelva legal y objetivamente el tema de la regulación expropiatoria, serían de gran utilidad a la hora de enfrentar estos problemas en nuestra realidad, los cuales intentaremos abordar en una futura oportunidad.

Debemos agregar, finalmente, la necesidad que el concepto de regulación expropiatoria se abra paso en nuestro sistema jurídico, tanto en tribunales como en la doctrina. No se trata, por cierto, de aceptar modelos ajenos, sino de ver, bajo un espectro más amplio, cómo amparamos al individuo de la acción a veces abusiva del Estado. Solo de esta manera nos convertiremos en una Nación desarrollada, donde verdaderamente el hombre, en su dimensión espiritual y material, tenga primacía sobre el Estado. El derecho de propiedad constituye, en consecuencia, una de las piedras angulares de una sociedad libre, donde ciertamente tendremos el deber de investigar, desarrollar y proteger a la persona, su libertad y dignidad.

\section{BIBLIOGRAFÍA CITADA}

MaCGraW-Hill (1998): Bilingual dictionary of Legal Terms. (McGraw-Hill Publishers. Segunda edición) 554 pp.

Bond, Josh (1998): Eminent Domain In Georgia, 8 pp. [fecha de consulta: 4 agosto 2006]. Disponible en: http://www.inetnow.net/ jbond/eminent/abstrac+t.htm

\footnotetext{
70 Selmi (2002) p. 31; Michelman (1988) p. 1621; y el propio Roberts (2002) p. 20.

${ }^{71} \mathrm{El}$ profesor Juergensmeyer hace un extenso desarrollo de este tema en un trabajo que aborda la planificación desde una multiplicidad de ángulos. JUERGENSMEYER (1998) cap. 10.9.
} 
CARlton, John (1992): “Takings' Cases Don't Always Favor Takers”, en: Wall Street Journal nov.: p. 12.

EAGLE, Steven (1996): Regulatory Takings (Michie Law Publishers) 750 pp.

EPSTEIN, Richard (1985): Takings: Private Property and the Power of Eminent Domain. (Harvard Univ. Press) 362 pp.

EPSTEIN, Richard (2002): “Taking By Slivers”, National Law Journal, A21: pp. 32-42

FERMANDOIS Arturo. (2005): "Inaplicabilidad de Ley de Monumentos Nacionales", en: Sentencias Destacadas 2004, Una Mirada desde la perspectiva de las Politicas Públicas. (Instituto Libertad y Desarrollo) 350 pp.

FisCHEL, William (1995): Regulatory Takings: Law, Economics, and Politics (Harvard Univ. Press) 415 pp.

Juergensmeyer, Julian C. (1998): Land Use Planning And Control Law (West Group, Hornbook Series) 795 pp.

Kordesh, Maureen Straub (1996): “I Will Build My House With Sticks' The Splintering Of Property Interest Under The Fifth Amendment May Be Hazardous To Private Property", en: 20 Harvard E. Law. Rev. pp. 397-418.

LoCKE, John (1988): "An Essay Concerning Civil Government", Locke's To Treatises Of Government. (Cambridge University Press) 480 pp.

Marmolejo, Crispulo (2003): El Problema de las Regulaciones Expropiatorias (Regulatory Takings) y su Implicancia en los Sistemas de Inversión Extranjera (Memoria de Grado de Magíster, Universidad de Chile). Resumen en: Revista Realidad, $\mathrm{N}^{\circ} 78$.

Michelman, Frank (1987): “Takings”, en: 88 Columbia Law Review, pp. 1600-1622.

Peterson, Andrea (1989): “The Taking Clause’: In Search Of Underlying Principles”, en: California Law Review, vol. 77: pp. 1314-1341.

POSNER, Richard A. (2002): Economic Analysis of Law (Aspen Publishers) 721 pp.

RoberTs, E. Thomas, (2002): "Classifying Temporary Takings After Tahoe Sierra", en Wake Forest University, Public Law Research Paper, N²10: pp. 02-10.

POWELL, Richard Roy Belden y RoHAN, Patrick J. (2004): The Law of Real Property (M. Bender Ed.) 876 pp.

SAX, Joseph L. (1964): “Takings", Harvard Law Review vol. 77.701: pp. 717-729.

SElmi, Daniel P. (2002): "Moratoria And Categorical Takings" en: "Taking Sides On Taking Issues”, (T. Roberts Ed., Cap. 12). 